\title{
Left Ventricular Hypertrophic Patterns and Wall Motion Dynamics in Hypertrophic Cardiomyopathy: An Electron Beam Computed Tomographic Study
}

\author{
Mariko Yoshida and Toshihiko TAKAмото*
}

\begin{abstract}
To investigate the left ventricular hypertrophic patterns and wall motion dynamics in hypertrophic cardiomyopathy, 51 patients were studied using electron beam computed tomography. The subject consisted of 26 asymmetrical hypertrophy, 9 diffuse hypertrophy, 14 apical hypertrophy and 2 papillary muscle hypertrophy. Concerning the wall motion dynamics in hypertrophic wall, 7 demonstrated homogeneous wall thickening involving the non-hypertrophic wall, 36 showed decreased wall thickening, 6 showed normal wall thickening, and 2 cases of papillary muscle hypertrophy had increased wall thickening in the apical wall. The percent wall thickening in hypertrophic wall was significantly reduced in relation to the increase of wall thickness; $14 \pm 8 \%$ in the wall over $20 \mathrm{~mm}, 23 \pm 12 \%$ in $16-19 \mathrm{~mm}$ and $56 \pm 36 \%$ in $13-15 \mathrm{~mm}$. The reduced wall motion dynamics in hypertrophic wall were clearly observed by electron beam computed tomography.
\end{abstract}

(Internal Medicine 36: 263-269, 1997)

Key words: percent wall thickening, asymmetrical hypertrophy, diffuse hypertrophy, apical hypertrophy

\section{Introduction}

Concerning the cardiac wall motion dynamics in systole in patients with hypertrophic cardiomyopathy (HCM), left ventricular septum and anterior wall motion dynamics have been investigated by cineangiography and echocardiography (1-5). However, a detailed study on the whole left ventricular wall including the apex has yet to be made. The present study investigated the left ventricular hypertrophic patterns, and the wall motion dynamics in the hypertrophic and non-hypertrophic sites in systole in patients with HCM. Electron beam computed tomography (EBCT) was employed because the method enabled the dynamic scanning of the whole heart with high scan speed of $50 \mathrm{msec}$ and multiple slices covering from the base to the apex $(6,7)$.

\section{Subjects and Methods}

The patients studied were 41 males and 10 females with hypertrophic cardiomyopathy, and the mean age ( \pm S.D.) was $53 \pm 11$ years-old. The clinical diagnosis of hypertrophic cardio- myopathy was determined by clinical history, electrocardiography, two-dimensional echocardiography, and cardiac catheterization. The definition of hypertrophic cardiomyopathy was based on the report from the WHO/ISFC task force (8); left and right ventricular hypertrophy, asymmetric septal hypertrophy, and typical morphological changes of myocyte hypertrophy and disarray. Patients who had a history of hypertension or known cause of systemic diseases proved by endomyocardial biopsy studies were excluded.

EBCT (Imatron C-100), based on the magnetic deflection of an electron beam, was done with ECG synchronized multilayer cine mode ( $8 \mathrm{~mm}$ thick tomographic slice, $50 \mathrm{msec}$ scan). The long axis view of the left ventricle was obtained by angling the table 25 degrees of slew toward the patient's left side, and the short axis view at the papillary muscle level by angling the table 25 degrees of slew toward the patient's right side and tilting with 15 degrees downward. Forty $\mathrm{ml}$ of non-ionic contrast medium (300 mg iodine/ml) was administered intravenously from the antecubital vein through a 20 gauge teflon needle using a mechanical injector. Immediately after the injection, the EBCT scan was started. The distribution of wall hypertrophy

From the Second Department of Internal Medicine, Tokyo Medical College, Tokyo and *the Department of Cardiology, Sasaki Institute Kyoundo Hospital Received for publication June 27, 1996; Accepted for publication January 21, 1997

Reprint requests should be addressed to Dr. Mariko Yoshida, the Second Department of Internal Medicine, Tokyo Medical College, 6-7-1 Nishi-Shinjyuku, Shinjyuku-ku, Tokyo 160 
was assessed on the end-diastolic image. The evaluation of wall motion dynamics was made by the frame-by-frame analysis of 16 serial tomographic slice images per second. Left ventricular epicardial and endocardial boundaries in end-diastolic and endsystolic images were traced using a digitized computer analysis system (Freeland Prism 5000R: TomTec Co., Ltd., Boulder, Colorado). The left ventricle was divided into 100 segments by a centerline method and the mean of 5 segments was used to indicate left ventricular wall thickness. Trabeculation and/or muscle bands were disregarded in the identification of the endocardial surface. The percent wall thickening was determined by the following equation:

The percent wall thickening =

[[(wall thickness in end-systole) - (wall thickness in enddiastole)] / (wall thickness in end-diastole) $] \times 100$

As for wall motion we defined $40-100 \%$ as normal, less than $40 \%$ as decreased and more than $100 \%$ as increased. We also defined left ventricular hypertrophy as a left ventricular wall which exceeds $13 \mathrm{~mm}$ in thickness and right ventricular hypertrophy as a right ventricular wall of over $6 \mathrm{~mm}$. Papillary muscle hypertrophy was considered where the diameter of the papillary muscle was greater than the normal free wall thickness of the left ventricle.

\section{Results}

\section{Left ventricular hypertrophic patterns}

Left ventricular hypertrophic patterns in all 51 patients are summarized in Table 1, and were classified as follows; asymmetrical hypertrophy $26(51 \%)$, diffuse hypertrophy of the whole left ventricular walls 9 (18\%), apical hypertrophy (APH) (Fig. 1) 14 (27\%), and papillary muscle hypertrophy without left ventricular hypertrophy 2 (4\%). Of 26 with asymmetrical hypertrophy, 21 had asymmetrical septal hypertrophy (ASH) (Fig. 2), 3 lateral hypertrophy (Fig. 3), and 2 posteroseptal and lateral hypertrophy which were previously reported as Maron's Classification Type IV (9). Among all the cases, right ventricular hypertrophy was observed in 6 patients ( 4 with ASH and 2 with APH), 5 of whom demonstrated prominent wall hypertro- phy of greater than $20 \mathrm{~mm}$ in the left ventricle. There were also 9 patients with midventricular obstruction of the left ventricle, 8 of whom were accompanied with papillary muscle hypertrophy. The remaining one patient demonstrated prominent septal wall hypertrophy at the midventricular level.

\section{Left ventricular wall motion dynamics (Table 2)}

Concerning the left ventricular wall motion dynamics in systole, there were 7 patients (14\%) demonstrating homogeneous wall thickening. However, 36 patients $(71 \%)$ revealed decreased wall thickening at the hypertrophic site and normal/ increased wall thickening at the non-hypertrophic site. There were $6(12 \%)$ whose wall thickening of the hypertrophic site was normal but that of the non-hypertrophic site was increased. The remaining 2 patients (4\%) with papillary muscle hypertrophy alone demonstrated increased wall thickening of the apex and posterolateral wall.

Concerning the cavital morphology of the apex in systole, 9 $(35 \%)$ of 26 patients with asymmetrical hypertrophy demonstrated a spade-like or slit-like form due to disappearance of the apical ventricular cavity. A similar cavital morphological change was also observed in $9(64 \%)$ of 14 patients with APH, and 2 (22\%) of 9 patients with diffuse hypertrophy. In 2 patients with papillary muscle hypertrophy alone, the wall thickening of the apex was increased by more than $100 \%$.

The percent wall thickening and the amplitude of wall thickening at the left ventricular maximum hypertrophic site was estimated in relation to the severity of wall hypertrophy. As shown in Fig. 4, the percent and the amplitude of wall thickening were $13.9 \pm 7.7 \%$ and $3.2 \pm 1.7 \mathrm{~mm}$ in severe hypertrophic wall (more than $20 \mathrm{~mm}$ of thickness), $23.2 \pm 12.4 \%$ and $4.1 \pm 2.2$ $\mathrm{mm}$ in moderate hypertrophic wall (16-19 $\mathrm{mm}$ of thickness), and $55.5 \pm 36.0 \%$ and $7.3 \pm 4.6 \mathrm{~mm}$ in mild hypertrophic wall (13-15 mm of thickness). The percent wall thickening was also estimated at the whole segments in long and short axis projection views. The larger the hypertrophy of the wall the more significantly reduced was the percent wall thickening in systole (Fig. 5).

Table 1. Left Ventricular Hypertrophic Patterns in 51 Subjects

\begin{tabular}{lcccc}
\hline & $\begin{array}{c}\text { No. of } \\
\text { cases }\end{array}$ & $\begin{array}{c}\text { Right ventricular } \\
\text { hypertrophy }\end{array}$ & $\begin{array}{c}\text { Midventricular } \\
\text { obstruction }\end{array}$ & $\begin{array}{c}\text { Negative T wave } \\
(>10 \mathrm{~mm})\end{array}$ \\
\hline Asymmetrical hypertrophy & 26 & 4 & 5 & 19 \\
$\quad$ (Asymmetrical septal hypertrophy) & $(21)$ & $(4)$ & $(5)$ & $(14)$ \\
(Lateral hypertrophy) & $(3)$ & & & $(3)$ \\
$\quad$ (Maron type IV) & $(2)$ & & 1 & 7 \\
Diffuse hypertrophy & 9 & 2 & 3 & 12 \\
Apical hypertrophy & 14 & & & 2 \\
Normal wall thickness & 2 & & 9 & 40 \\
$\quad$ (Papillary muscle hypertrophy) & & 6 & & \\
\hline \multicolumn{1}{c}{ Total } & 51 & & & \\
\hline
\end{tabular}


A

Diastole

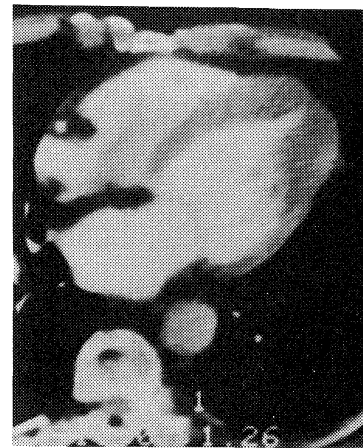

Systole

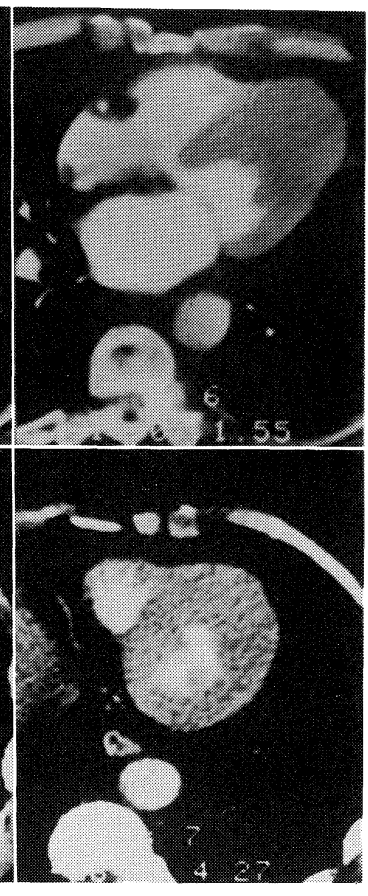

B

Diastole

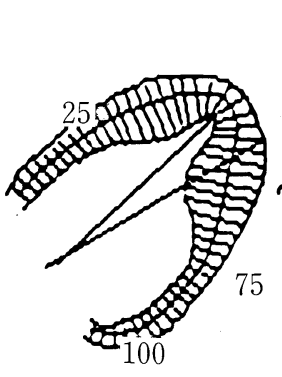

75

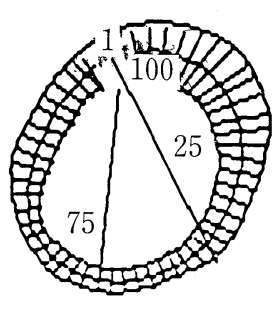

Systole
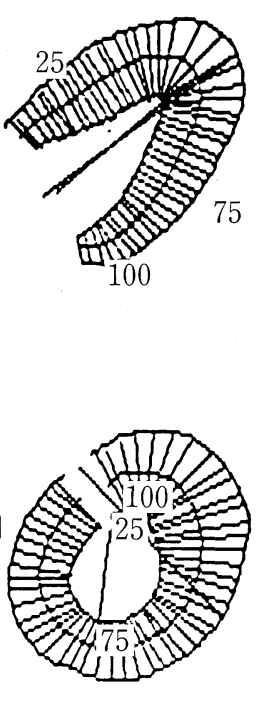

C

Segmental wall thickening
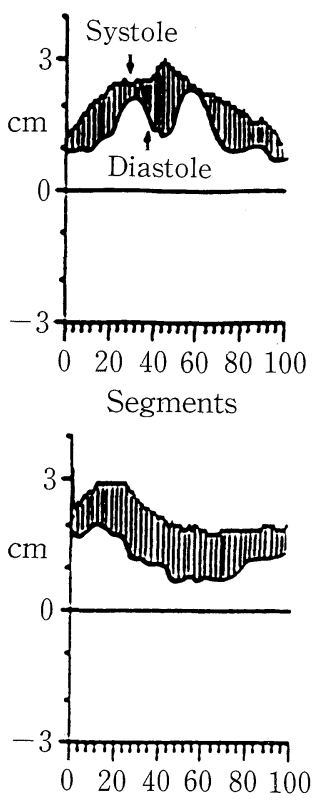

Segments

Figure 1. A 65-year-old male patient with apical hypertrophy. (A) A set of end-diastolic and end-systolic views in both long axis and short axis views obtained by cine mode electron beam computed tomography. Short axis views were obtained at the papillary muscle level. (B) The epicardial and endocardial boundaries in end-diastolic and end-systolic images were traced and divided into 100 segments by a centerline method. Trabeculation and/or muscle bands were disregarded in the identifying of the endocardial surface. (C) The wall thickness in each segment was traced, and the shaded area indicated the increment of the systolic wall thickening. It was noted that the increment of systolic wall thickening was reduced at the apical hypertrophic segments. The cavital morphology of the true apex in diastole was thin and revealed a spade-like form.

\section{Discussion}

Echocardiography has been employed to investigate the ventricular septum and posterior wall motion in systole in patients with hypertrophic cardiomyopathy (HCM), but uniform observations have yet to be obtained. Adelman et al (1) have made cineangiographic observations and reported increased wall motion of the ventricular septum in patients with asymmetric septal hypertrophy (ASH). While Rossen et al (2) with M-mode echocardiography and Redwood et al (3) with biplane cineangiography reported that the wall motion was decreased. According to the two-dimensional echocardiographic study by Kaul et al (4) the wall motion in the lower septum was increased despite the decrease in the base and middle septum wall motion. Cohen et al (5) and Silverman et al (10) reported that the ventricular septal wall motion was decreased but that the posterior wall motion was increased in patients with idiopathic hypertrophic subaortic stenosis. Inadequate resolution of the lateral wall is a disadvantage of echocardiography. It is also difficult to accurately capture the endocardial surface of the apex by echocardiography. Depending on physique or thickness of the patient's thorax, it is frequently too obscure to obtain favorable images by this method. Since with EBCT the whole heart can be observed without worry over those disadvantages $(6,7)$, it is considered as an excellent method to observe irregular wall hypertrophy and the morphology of the apex as well as the wall motion dynamics including the apex in systole in patients with HCM.

\section{Left ventricular hypertrophic pattern}

HCM is primarily characterized by its asymmetric septal hypertrophy (11). However, there have been reports on the rare cases of apical hypertrophy and diffuse hypertrophy (12). In the present study using EBCT, ASH was observed in the largest number of subjects ( 21 cases, $41 \%$ ) followed by APH ( 14 cases, $27 \%$ ) and diffuse hypertrophy (9 cases, 18\%) (Table 1). The incidence of APH is varied depending on the population studied: it was 3\% according to the report by Wigle et al (13) and $17 \%$ by Shapiro and Mckenna (14). Hada et al (15) reported the incidence among Japanese people to be at $23 \%$. It is known that 
A

Diastole
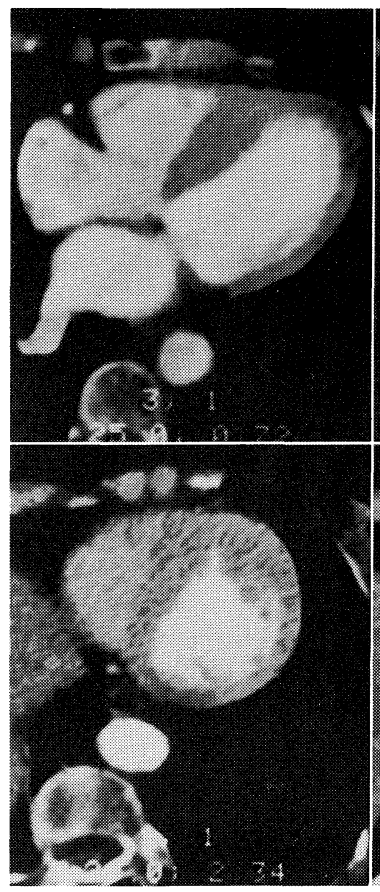

Systole

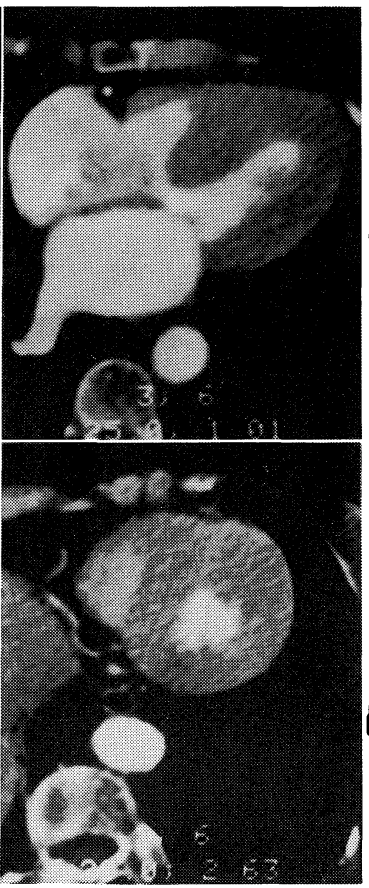

$\mathrm{B}$

Diastole

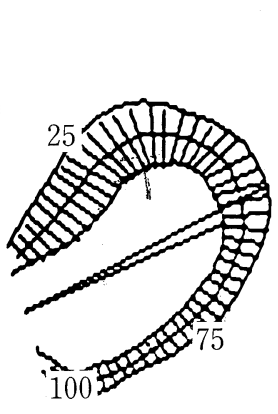

Systole
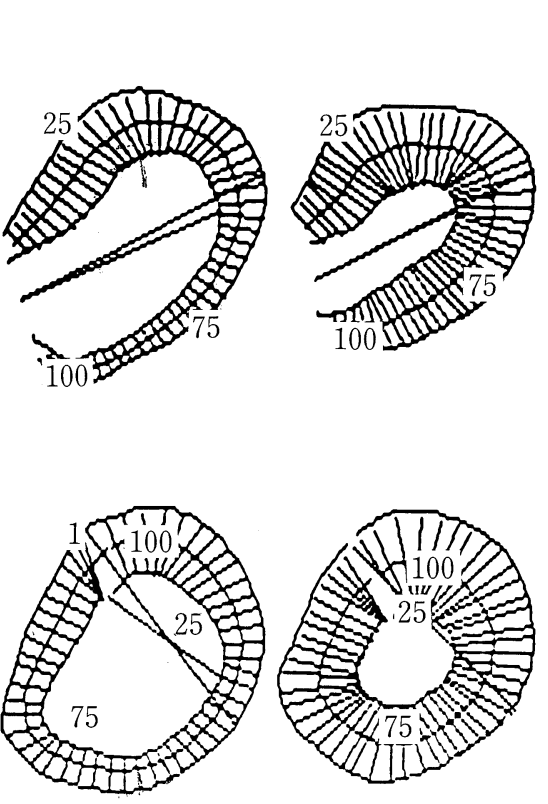

C

Segmental wall thickening
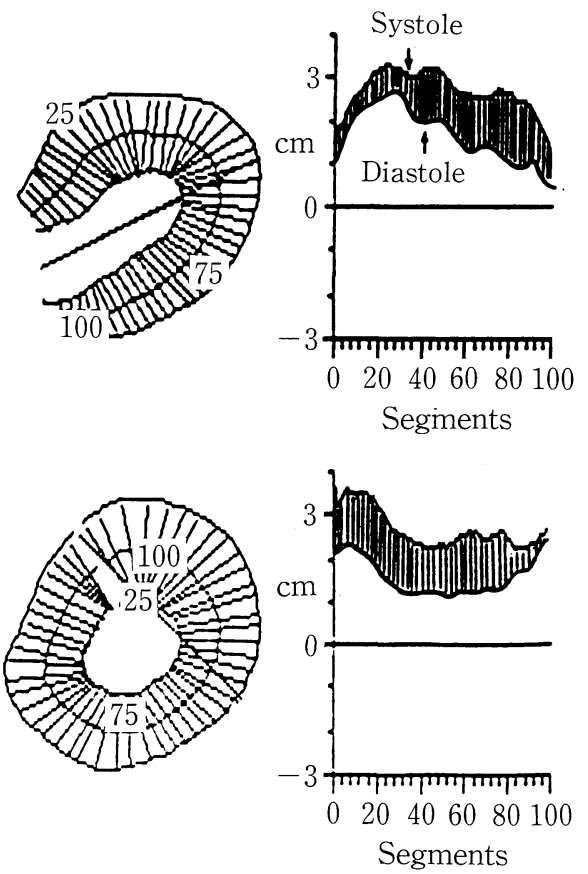

Figure 2. A 66-year-old female patient with asymmetrical septal hypertrophy. (A) Long and short axis tomographic views obtained by the same manner as that in Fig. 1.(B) The schematic illustration of epicardial and endocardial boundaries in 100 segments. (C) Segmental systolic wall thickening at the hypertrophic sites of anterior, anteroseptal and anterolateral walls was prominently reduced.

the incidence of APH is high among the Japanese. In the present study, APH was also observed in $27 \%$ of the subjects. The papillary muscle hypertrophy was observed in $32(67 \%)$, and it was also noted in 8 of the 9 patients with midventricular obstruction. Midventricular obstruction was observed in one advanced ASH case which had no hypertrophy of papillary muscles. The $2 \mathrm{APH}$ cases in which the apex become thinner in the systole showed the midventricular obstruction. This indicates that the midventricular obstruction is related to not only reduced contraction of the apex but also to papillary muscle hypertrophy and advanced irregular hypertrophy of the left ventricle. The wall thickness of the hypertrophic site in the left ventricle was greater than $20 \mathrm{~mm}$ in 5 of the 6 patients demonstrating hypertrophy of right ventricle. The incidence of accompanying right ventricular hypertrophy was high in the cases with advanced left ventricular hypertrophy. This indicates that right ventricular hypertrophy is related to the extent of left ventricular hypertrophy.

\section{Left ventricular wall motion dynamics in systole}

Of the 51 patients with HCM investigated in the present study, decreased wall thickening in the hypertrophic site of left ventricle was observed in $36(71 \%)$ (Table 2). The pathology of
HCM includes micro coronary circulation disorder due to mechanical narrowing of the intramural coronary artery (16), spasm of the small coronary artery (17), myocardial disorder by calcium overload, abnormality in the catecholamine sympathetic nervous system $(18,19)$, and abnormal mitochondria metabolism have been reported (20). However, it was yet to be clarified whether or not the disorder is localized in the hypertrophic site or not. Perrone-Filardi et al (21) reported that the glucose uptake in the hypertrophic septum was decreased compared to the left ventricular free wall. Pathologically, Maron et al (22) reported that cardiac muscle cell disorganization was also observed in the non-hypertrophic site and that the incidence was higher in the septum region than in the left ventricular free wall. Unverferth et al (23) and Tanaka et al (24) reported that myocardial fibrosis was observed in both the septum and the left ventricular free wall but more fibrosis was noted in the former. According to St John Sutton et al (25), fiber disarray was increased in hypertrophic obstructive cardiomyopathy (HOCM), and the tendency for a higher increase was noted in the septum compared to the left ventricular free wall. The above reports indicated that the lesion was noted in both the septum and the left ventricular free wall in the patients with $\mathrm{HCM}$, and that the lesion was more marked in the septum which 
A

Diastole
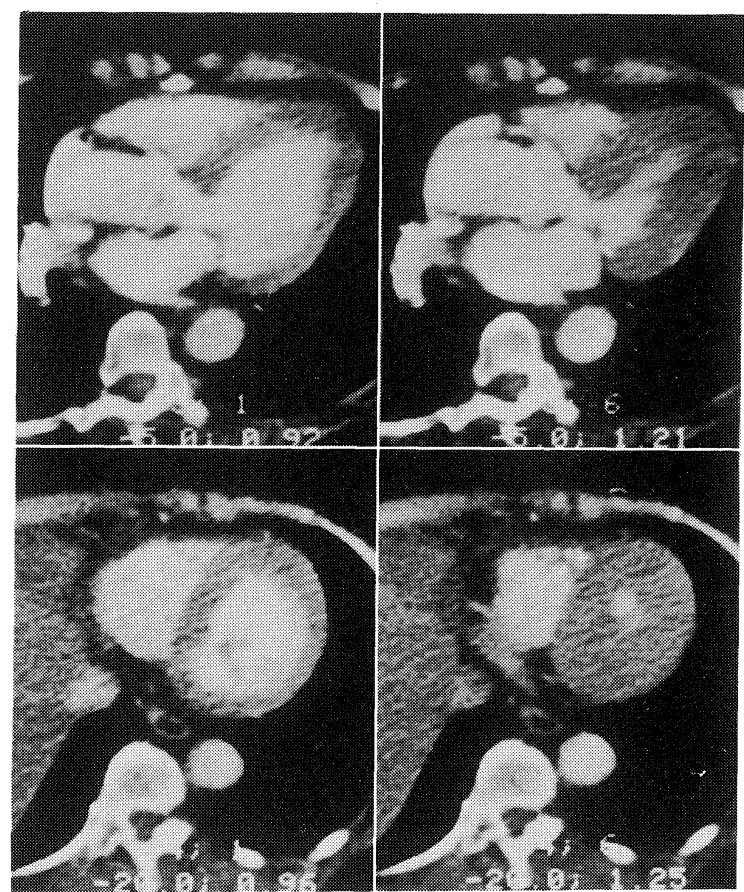

Diastole

Systole

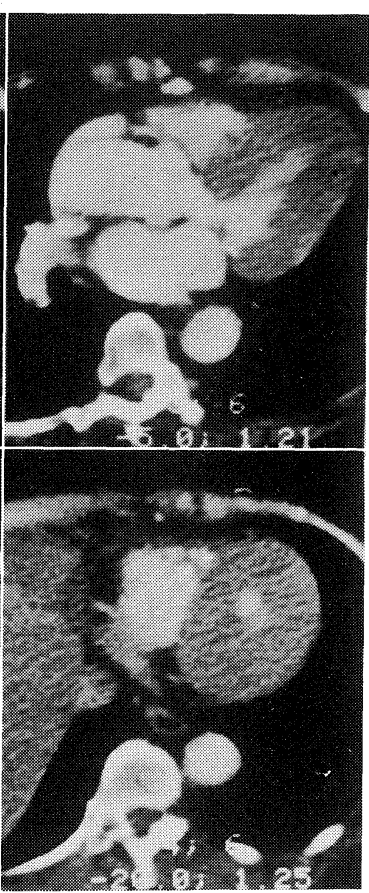

Systole

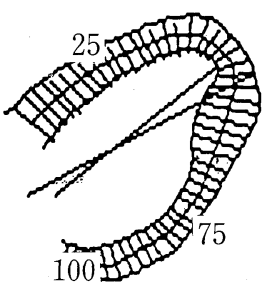

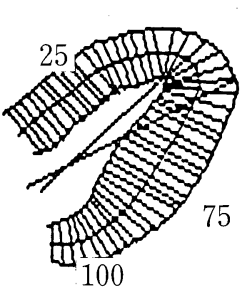

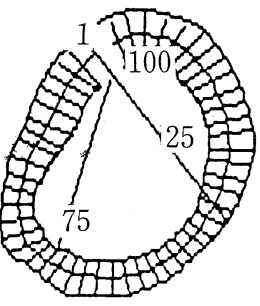

B

C

Segmental wall thickening
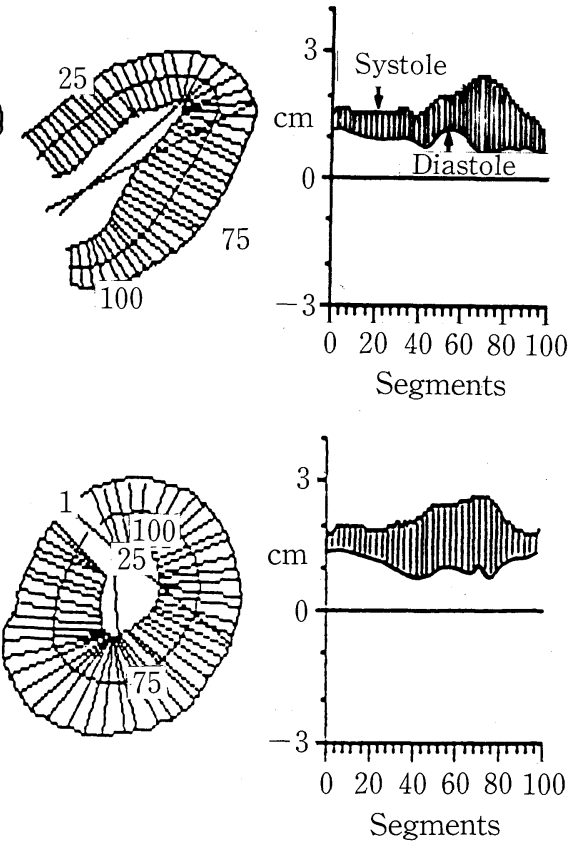

Figure 3. A 63-year-old female patient with lateral hypertrophy. Although the lateral wall hypertrophy was very mild in diastole, prominent augmentation of the systolic wall thickening at posterolateral to posterior wall segments was observed. The electrocardiographic findings in this patient revealed the deep negative $T$ wave in the left precordial leads $\left(V_{3}-V_{6}\right)$. The computed tomographic views $(A)$ and schematic illustrations $(B)$ of the left ventricular wall boundary tracing were obtained in the same manner.

Table 2. Left Ventricular Wall Motion Dynamics in Systole

\begin{tabular}{|c|c|c|c|c|c|}
\hline & $\begin{array}{l}\text { No. of } \\
\text { cases }\end{array}$ & $\begin{array}{c}\text { Homogeneous } \\
\text { wall } \\
\text { thickening }\end{array}$ & $\begin{array}{l}\text { Hypertrophic site: } \\
\text { decrease }\end{array}$ & $\begin{array}{l}\text { Hypertrophic site: } \\
\text { normal }\end{array}$ & $\begin{array}{l}\text { Normal wall } \\
\text { thickness: } \\
\text { partial increase }\end{array}$ \\
\hline Asymmetrical hypertrophy & 26 & 2 & 21 & 3 & \\
\hline Diffuse hypertrophy & 9 & 3 & 6 & & \\
\hline Apical hypertrophy & 14 & 2 & 9 & 3 & \\
\hline $\begin{array}{l}\text { Normal wall thickness } \\
\text { (Papillary muscle hypertrophy) }\end{array}$ & 2 & & & & 2 \\
\hline Total & 51 & 7 & 36 & 6 & 2 \\
\hline
\end{tabular}

was the hypertrophic site. The extent of the lesions in the hypertrophic sites other than the septum has not been clarified, but it was assumed that the lesion was more advanced and the wall thickening was reduced in the hypertrophic sites. Figures 4 and 5 indicate that the larger the hypertrophy, the more decreased the wall thickening of the hypertrophic sites. Thus, it was considered that the larger the hypertrophy, the more marked the lesion and the more reduced the wall thickening.
In many cases in the ASH group, wall thickening was increased in the posterolateral to posterior wall of the opposite side which represent non-hypertrophic sites. Increased wall thickening of the posterior wall which was non-hypertrophic was also observed in the APH group. Cohen et al (5) and Silverman et al (10) reported increased wall thickening of posterior wall in patients with HCM. It was considered that the motion was more increased in the posterior wall than in the 


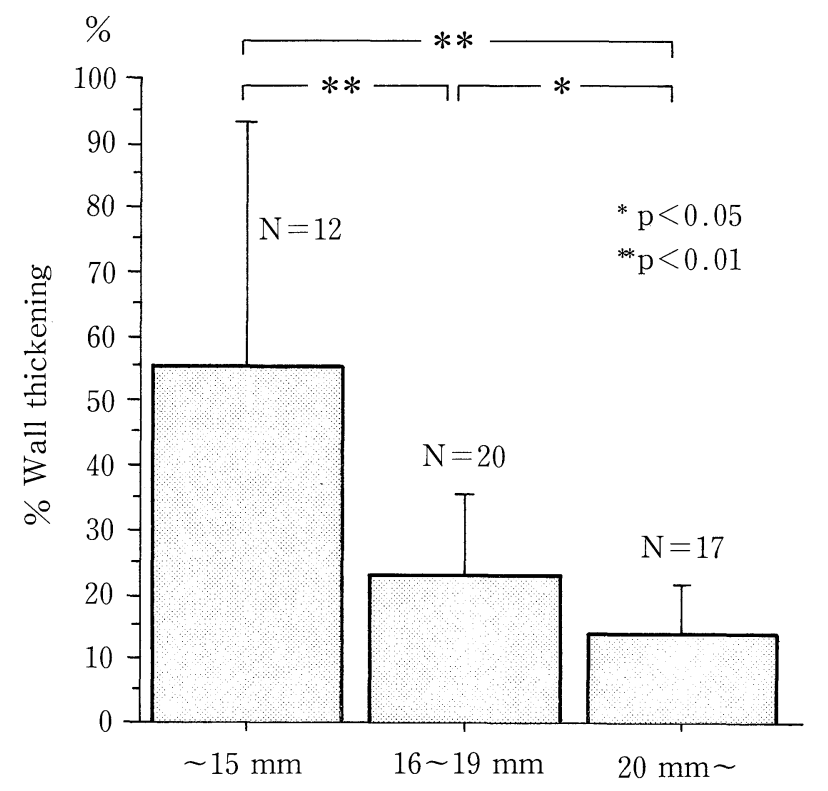

Wall thickness

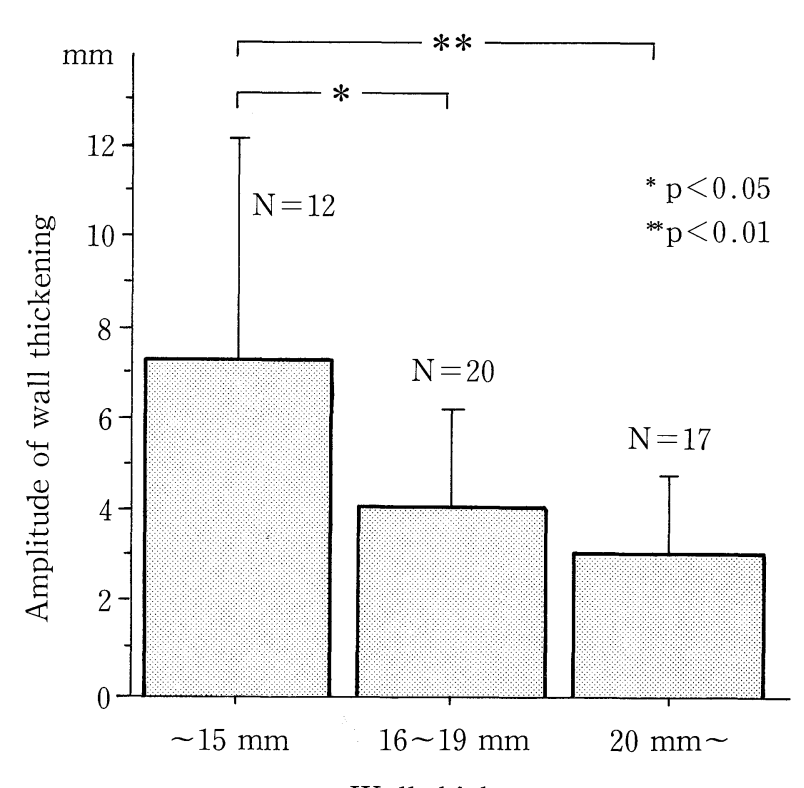

Wall thickness

Figure 4. Left: The correlation between $\%$ wall thickening and wall thickness. Right: The correlation between the amplitude of wall thickening and wall thickness. The larger the wall thickness the smaller the \% wall thickening and amplitude of wall thickness.
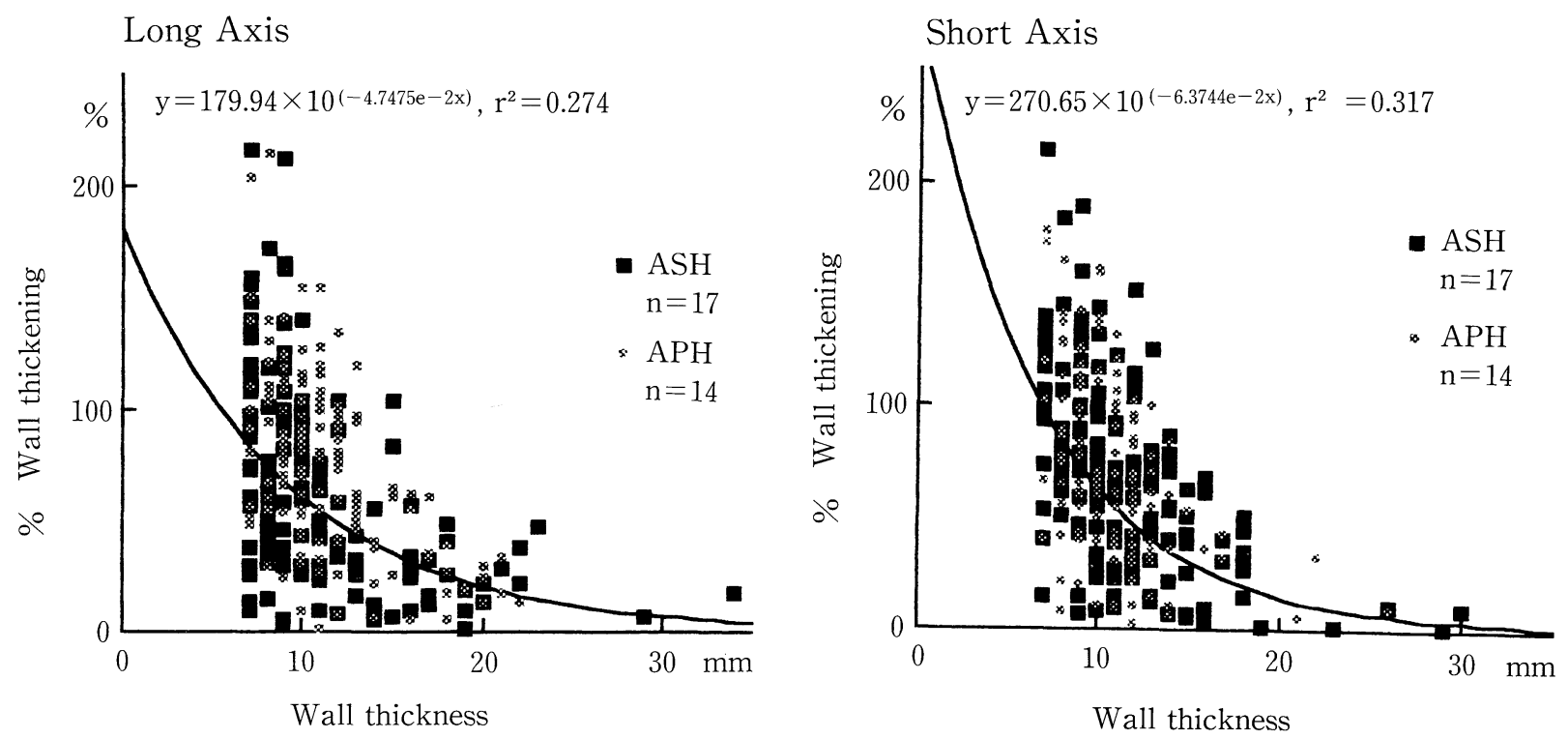

Figure 5. The correlation between the \% wall thickening and wall thickness estimated at 310 segments (10 segments $\times 31$ cases) in patients with asymmetrical septal hypertrophy and apical hypertrophy. Left: The data collected in a long axis view. Right: The data collected in a short axis view. The exponential fitting curve revealed the reduced systolic wall thickening in hypertrophic sites.

septum in ASH because the degree of myocardial lesion is more mild. In ASH, in which the septum wall motion is decreased, the posterolateral to posterior wall motion in the opposite side is assumed to be increased as a compensation.
Concerning the cavital morphology of the apex, those demonstrating spade-like or slit-like form in systole accounted for $65 \%$ in the APH, 35\% in the asymmetrical hypertrophy and $22 \%$ in the diffuse hypertrophy. The wall thickening of the apex 


\section{Wall Motion Dynamics in HCM}

was increased in ASH and in diffuse hypertrophy. On the other hand, $7(50 \%)$ of the 14 patients in the APH demonstrated a spade-like or oblong banana form of apex in systole. Despite the decreased wall motion of the apex which was the hypertrophic site, the incidence of a spade or slit-like form during systole was high because of the narrowing of the lumen of the apex. Though the morphology of the apex seemed similar in systole, the wall motion dynamic differed between the ASH and APH groups.

\section{Conclusion}

The present study demonstrated characteristics of the left ventricular wall morphology and wall motion dynamics in a large number of hypertrophic cardiomyopathy patients. The larger the hypertrophic wall in cardiomyopathy, the more reduced or deteriorated the contraction. Compensatory hyperdynamic wall motion was often seen in the normally thick portion of the left ventricular wall. The impaired myocardial contraction in the hypertrophic segments may be caused by myocardial fiber degeneration and/or disarray. Electron beam computed tomography seemed to be an accurate methodology to evaluate the left ventricular wall dynamics.

\section{References}

1) Adelman AG, McLoughlin MJ, Marquis $Y$, Auger P, Wigle ED. Left ventricular cineangiographic observations in muscular subaortic stenosis. Am J Cardiol 24: 689, 1969.

2) Rossen RM, Goodman DJ, Ingham RE, Popp RL. Ventricular systolic septal thickening and excursion in idiopathic hypertrophic subaortic stenosis. N Engl J Med 291; 1317, 1974.

3) Redwood DR, Scherer JL, Epstein SE. Biventricular cineangiography in the evaluation of patients with asymmetric septal hypertrophy. Circulation 49: $1116,1974$.

4) Kaul S, Tei C, Shah PM. Interventricular septal and free wall dynamics in hypertrophic cardiomyopathy. J Am Coll Cardiol 1: 1024, 1983.

5) Cohen MV, Cooperman LB, Rosenblum R. Regional myocardial function in idiopathic hypertrophic subaortic stenosis. An echocardiographic study. Circulation 52: 842, 1975.

6) Boyd DP, Gould RG, Quinn JR, Sparks R, Stanley JH, Herrmannsfeldt WB. A proposed dynamic cardiac 3-D densitometer for early detection and evaluation of heart disease. IEEE Trans Nucl Science NS-26: 2724 , 1979.

7) Boyd DP, Lipton MJ. Cardiac computed tomography. Proc IEEE 71:298, 1983.

8) Richardson P, McKenna W, Bristow M, et al. Report of the 1995 World Health Organization/International Society and Federation of Cardiology Task Force on the Definition and Classification of cardiomyopathies. Circulation 93: 841, 1996 (news).
9) Maron BJ, Gottdiener JS, Epstein SE. Patterns and significance of distribution of left ventricular hypertrophy in hypertrophic cardiomyopathy. A wide angle, two dimensional echocardiographic study of 125 patients. Am J Cardiol 48: 418, 1981.

10) Silverman KJ, Hutchins GM, Weiss JL, Moore GW. Catenoidal shape of the interventricular septum in idiopathic hypertrophic subaortic stenosis: two dimensional echocardiographic confirmation. Am J Cardiol 49: 27 , 1982.

11) Henry WL, Clark CE, Epstein SE. Asymmetric septal hypertrophy. Echocardiographic identification of the pathognomonic anatomic abnormality of IHSS. Circulation 47: 225, 1973.

12) Maron BJ.Asymmetry in hypertrophic cardiomyopathy: the septal to free wall thickness ratio revisited. Am J Cardiol 55: 835, 1985.

13) Wigle ED, Sasson Z, Henderson MA, et al. Hypertrophic cardiomyopathy. The importance of the site and the extent of hypertrophy. A review. Prog Cardiovasc Dis 28: 1, 1985.

14) Shapiro LM, Mckenna WJ. Distribution of left ventricular hypertrophy in hypertrophic cardiomyopathy: a two-dimensional echocardiographic study. J Am Coll Cardiol 2: 437, 1983.

15) Hada Y, Sakamoto T, Amano K, et al. Prevalence of hypertrophic cardiomyopathy in a population of adult Japanese workers as detected by echocardiographic screening. Am J Cardiol 59: 183, 1987.

16) James TN, Marshall TK. De subitaneis mortibus. XII. Asymmetrical hypertrophy of the heart. Circulation 51: 1149, 1975.

17) Factor SM, Minase T, Cho S, Dominitz R, Sonnenblick EH. Microvascular spasm in the cardiomyopathic syrian hamster: a preventable cause of focal myocardial necrosis. Circulation 66: 342, 1982.

18) Tomanek RJ, Bhatnagar RK, Schmid P, Brody MJ. Role of catecholamines in myocardial cell hypertrophy in hypertensive rats. Am J Physiol 242: H1015, 1982

19) Raum WJ, Laks MM, Garner D, Swerdloff RS. Beta-adrenergic receptor and cyclic AMP alterations in the canine ventricular septum during longterm norepinephrine infusion: implications for hypertrophic cardiomyopathy. Circulation 68: 693, 1983.

20) Kako KJ, Thornton MJ, Heggtveit HA. Depressed fatty acid and acetate oxidation and other metabolic defects in homogenates from hearts of hamsters with hereditary cardiomyopathy. Circ Res 34: 570. 1974.

21) Perrone-Filardi P, Bacharach SL, Dilsizian V, Panza JA, Maurea S, Bonow RO. Regional systolic function, myocardial blood flow and glucose uptake at rest in hypertrophic cardiomyopathy. Am J Cardiol 72: 199, 1993.

22) Maron BJ, Anan TJ, Roberts WC. Quantitative analysis of the distribution of cardiac muscle cell disorganization in the left ventricular wall of patients with hypertrophic cardiomyopathy. Circulation 63: 882, 1981.

23) Unverferth DV, Baker PB, Pearce LI, Lautman J, Roberts WC. Regional myocyte hypertrophy and increased interstitial myocardial fibrosis in hypertrophic cardiomyopathy. Am J Cardiol 59: 932, 1987.

24) Tanaka M, Fujiwara H, Onodera T, Wu DJ, Hamashima Y, Kawai C. Quantitative analysis of myocardial fibrosis in normals, hypertensive hearts, and hypertrophic cardiomyopathy. Br Heart J 55: 575, 1986.

25) St John Sutton MG, Lie JT, Anderson KR, O’Brien PC, Frye RL. Histopathological specificity of hypertrophic obstructive cardiomyopathy: myocardial fibre disarray and myocardial fibrosis. Br Heart J 44: 433, 1980. 